\title{
Research on Promoting Effect of Tourism Industry Development on Tourism Poverty Alleviation in Guizhou
}

\author{
Siqi Li, Mu Zhang, Xinpu Wang \\ School of Finance, Guizhou University of Finance and Economics, Guiyang 550025, China \\ E-mail:546932209@qq.com,rim_007@163.com,1207112376@qq.com \\ Received December14, 2017 \\ Accepted March 3, 2018
}

\begin{abstract}
The traffic in the counties of Guizhou is inconvenient and the economic location is remote. How to transform the characteristics of natural resources and national cultural resources into economic advantages? This is the key of this paper. In this paper, the tourism industry of 50 poverty-stricken counties in Guizhou province is selected as the representative, and the anti-poverty effect of Guizhou tourism industry is measured by using panel data model. The empirical results show that the development of tourism industry in 50 poverty-stricken counties in Guizhou has promoted the development of the national economy, thus reducing the poverty rate of the counties. It is concluded that Guizhou tourism industry has a certain promoting effect on the precision poverty alleviation in Guizhou.
\end{abstract}

Keywords: Tourism Industry, Guizhou County, Targeted Poverty Alleviation, Panel Data Model.

\section{Preface}

The development of Guizhou's socioeconomic development and the gap between the developed regions of the eastern coastal areas requires the development of Guizhou. However, how to realize the crossing has always been a problem for Guizhou's development. Despite the advantages of learning, imitation, development and opportunities, at the same time, inequality, the existence and development foundation development assignments, endogenous dynamic development mechanism is difficult to establish, and many other factors. At present, the academic circles mainly analyze how to develop the characteristic industries of this underdeveloped region from the perspectives of culture, technology and management, but make quantitative analysis from the perspective of economics is less. This article explores the promotion function of tourism industry development to the accurate poverty alleviation in Guizhou counties, and provides some theoretical and empirical research for the economic development of Guizhou province to make up for the deficiency of this research.

\section{Writing background}

At present, our country is in an extraordinary period of accelerating the transformation of the mode of economic growth. General Secretary Jinping Xi stressed at the 2014 National Economic work Conference that the relationship between sustained economic development and GDP growth should be correctly dealt with in future work. Development is not equal to the increase of GDP, accelerating the adjustment of industrial structure, maintaining the rational and stable growth of the national economy, and realizing the sustainable development of the economy in the future, that is, the economic growth can not be measured by digital GDP alone. It is necessary to coordinate the development of industry, ensure the process of industrialization and urbanization, and develop modern agriculture to ensure food security, stabilize the price level, and at the same time, ensure stable growth. Employment should also protect people's livelihood. Preliminary accounting by the National Bureau of Statistics: in 2013, China's GDP was 56.8845 trillion 
yuan, an increase of 7.7 percent, while Guizhou's GDP8006 grew by 12.5 percent, although Guizhou had a relatively fast growth. However, the economic level is still below the national average. Compared with other provinces and cities in the west, the economic level is still not high. If we want to achieve the overall well-off level in the whole province early, we must strive to solve the poverty problem, especially in the rural areas. At the same time, the gap between the rich and the poor is widening, especially the gap between urban and rural income is more prominent, urban and rural income The widening of the level gap does not only affect the reform of the rural production mode, the development of the agricultural market, and the farmers' enthusiasm for production. It will also have a significant impact on the overall level of economic development of the whole society. In the "outline for Poverty Alleviation and Development in China's Rural areas 2011-2020", published by the Public Office of the State Council for Poverty Alleviation in 2011, it is pointed out that the overall goal is to promote comprehensive and coordinated economic and social development in poverty-stricken areas. By 2020, the whole society will be able to build a well-off society in an all-round way and achieve common prosperity. At the same time, it is proposed that by 2015, the per capita net income of the poor will have doubled to more than 3000 yuan, and the number of poor people will have decreased by 15 percent. By 2020, the per capita net income of the poor will quadruple, with a net income of 6000 yuan, and the poor will achieve collective eradication of poverty and basically eliminate the phenomenon of absolute poverty. It is hoped that the overall goal of eradicating poverty and achieving a well-to-do life by 2020 will be achieved in advance of 2017. The main poverty-stricken areas in the country are concentrated in remote mountainous areas. At present, poverty relief work is mainly carried out in the poverty-stricken special zones of Guizhou. Of the 88 counties in Guizhou, 56 are focused on helping the poor and 48 are at the national level. It is urgent to eliminate poverty and promote economic development in Guizhou.

There are many international measure of poverty indicators, including poverty headcount, also called poverty gap, Sen poverty index, FGT poverty index, S index (SST) index system, we study the problem of poverty in Guizhou Province, combined with the mathematical statistics principle, to quantitative research, and taking into account the availability and regularity data show the data, select the poverty rate as the research object.

In the study of poverty in Guizhou Province, not only does the poverty problem of Guizhou Province be considered as a whole, but also goes deep into 88 counties (cities) of Guizhou Province. Therefore, it is more reasonable to consider the establishment of panel data model. Cross-Sectional data Series Pooled Crosssectional Data and Panel Data are three main economic data structure forms. Time series data and cross section data are all data sets with one dimension. Where time series data are individual variables in the observed values vary in sequence over a certain period of time; section data are spatial data of multiple individuals at a certain point in time. Panel data are formed by mixing time series and cross section data in time and cross section. The characteristics of individuals in time and cross-section can be reflected from different angles. Therefore, the study of panel data can take into account both the effect of time and the effect of influencing factors on a single variable. It is more comprehensive, more systematic and more stable than simple onedimensional data.

In addition, at present, most of the research on poverty tends to the emergence of poverty, the evolution of poverty and other qualitative analysis. There is no indepth study on the huge data released by the Guizhou Bureau of Statistics. Based on this situation, in order to make full use of the abundant data resources and make better quantitative research on the poverty problem, this paper intends to carry out a further study on the poverty problem in Guizhou Province.

\section{Literature Review}

\subsection{Domestic research status}

The articles and achievements of "targeted poverty alleviation" in domestic research are relatively limited, but some outstanding research ideas are also obtained. Feng Chen (2014) mentioned the need to improve the object recognition mechanism of poverty alleviation, and advocated the development of specific support plans and measures in accordance with the characteristics of different households in different villages ${ }^{[1]}$. Lijie Zhang (2016) pointed out that in the current our country economy under the macro background of the new normal, precise poverty 
alleviation work is facing new development opportunities, we must seriously implement the $\mathrm{Xi}$ general secretary precision poverty alleviation idea, promote the poverty alleviation work theory innovation, system innovation and mechanism innovation [2]. Qianqian Tang (2016) mentioned when it comes to "precise poverty alleviation" as the 18th national congress emphasis on the implementation of poverty alleviation strategy after the new policy, which is China's poverty alleviation work mechanism to construct important train of thought in the new period, but due to the vast and complex conditions, and the obvious regional difference, the accuracy of the national poverty alleviation in different regions would present different results ${ }^{[3]}$; Haiying Liu (2011) advocated providing a fair share of economic and social development to poor areas through poverty reduction initiatives ${ }^{[4]}$.

Domestic scholars for accurate precision knowledge poverty alleviation policy for poverty alleviation mechanism study is a reference, but for how to effectively carry out precise poverty alleviation work is still exist some missing, which provides a reference for the discussion and development of this thesis.

\subsection{Foreign research status}

Researches on poverty, foreign scholars have abundant theoretical achievements, especially the foreign research on the concept of poverty reduction. It has an important meaning to the construction and practice of our country's precision anti-poverty theory. Amartya (2016) attributed the causes of poverty to unequal enjoyment of rights, and the contradiction between rights and distribution resulted in the reality of poverty ${ }^{[5]}$. So, Amartya argues that the solution to the famine is to tackle inequality first. Not only that, but also to give the poor people the basic rights and equal opportunities in the production, exchange and circulation. Under the guidance of the Amartya theory, the Asian development bank in 2007 promoted the theory of poverty reduction with "equal opportunity" and "equitable sharing". This theory argues that the economic growth in earnings and the fair distribution to promote poverty reduction effect, to some extent, sharing type growth poverty reduction concept is "all equal opportunity or all share achievements" effective poverty reduction paradigm ${ }^{[6]}$.

All in all, experts and scholars have expressed their concerns and opinions. It is not easy to think that the role of government in the targeted poverty alleviation is very important and the poverty alleviation itself is very complicated and tedious work.

\section{Establishment of Panel Data Model}

\subsection{Overview of panel data}

Panel data refers to a collection of two dimensional data that is a combination of time series data and cross sectional data by intercepting multiple surfaces or multiple time points at a time sequence point.

The panel data is used to describe the data sets of individual data and time series formed by a specific individual through repeated observation, which is the three-dimensional information of time, section and individual: from the point of time series, panel data can describe changes over time of different changes in law; From the cross-sectional data, the differences between individual individuals at a particular point in the panel data. Its manifestations are as follows:

$$
\begin{gathered}
\mathrm{y}_{\mathrm{it}}=\alpha_{i t}+\beta_{1 t} x_{1 i t}+\ldots+\beta_{k t} x_{k i t}+\mu_{i t}, \\
i=1,2, \ldots, N ; t=1,2, \ldots, T
\end{gathered}
$$

Among them, $\alpha_{i t}$ represents the constant term of the model, $x=\left(x_{1 i t}, x_{2 i t}, \ldots, x_{k i t}\right)$ represents $K$ dependent variables in the model, And $\beta_{t}=\left(\beta_{1 t}, \beta_{2 t}, \ldots, \beta_{i t}\right)$ is the coefficient matrix for $K$ variables, $\mu_{i t}$ represents the random error terms and the assumptions that are satisfied: $\mu_{i t}$ are independent of each other, and the mean is 0 and the variance is $\sigma_{\mu}^{2}$ 。

\subsection{Panel data model}

The regression model based on panel data is called panel data model. Usually, linear panel data regression model is called panel data model. For convenience, linear panel data regression model is called panel data model. The general form of panel data model is:

$\mathrm{Y}_{i t}=\alpha_{i t}^{*}+\sum_{h=1}^{K} \beta_{h i t} x_{h i t}+u_{i t}, i=1,2, \ldots, \mathrm{N} ; \mathrm{t}=1,2, \ldots, \mathrm{T}$ Where $Y_{i t}$ is the observed value of the explained variable for the individual $i$ at $t, x_{h i t}$ is the $h$ th explanatory variable for the observation of individual $i$ at $t ; \beta_{\text {hit }}$ to be estimated for the $h$ th explanatory variable; $\mathrm{u}_{\mathrm{it}}$ is the random error term; the panel model is usually divided into three categories. 


\section{S. Li, M. Zhang}

That is, the mixed model, the fixed effect model and the random effect model, in which the fixed effect model $\alpha_{i t}{ }^{*}$ is a fixed parameter, and the random error term $\mathrm{u}_{\mathrm{it}}$ denotes the influence of the neglected variation with time or individual. And given the non-observational effect and the explanatory variable, the expectation of the random error term $u_{i t}$ is equal to zero. $u_{i t}$ has the same square difference, and different individuals and different points correspond to each other. $u_{i t}$ is independent of each other. Its model takes the form of:

$$
\mathrm{Y}_{i t}=\alpha_{\mathrm{t}}+\sum_{h=1}^{K} \beta_{h} x_{h i t}+u_{i t}
$$

If there are only individual effects in the model, the model form is as follows:

$$
Y_{i t}=\alpha_{i}+\sum_{h=1}^{K} \beta_{h} x_{h i t}+u_{i t}
$$

$\alpha_{i}$ as a random variable, this paper describes the difference between regression functions established by different individuals, which is called individual fixed effect model because it is not observable and is associated with the change of observable explanatory variable $X_{h i t}$.

If there is only a time effect in the model, the form of the model is:

$$
\mathrm{Y}_{i t}=\alpha_{\mathrm{t}}+\sum_{h=1}^{K} \beta_{h} x_{h i t}+u_{i t}
$$

$\alpha_{\mathrm{t}}$ as a random variable, this paper describes the difference between regression functions established by different individuals. Because it is not observable and is associated with the change of observable explanatory variable $x_{\text {hit }} \mathrm{t}$, it is called the time-point fixed effect model.

$$
\mathrm{Y}_{i t}=\alpha_{\mathrm{t}}+\gamma_{\mathrm{t}}+\sum_{h=1}^{K} \beta_{h} x_{h i t}+u_{i t}
$$

$\alpha_{i}$ is a random variable, indicating that there are $\mathrm{N}$ different intercept terms for $\mathrm{N}$ individuals, and their variation is related to $X_{i t}$, and $\gamma_{\mathrm{t}}$ is a random variable, indicating that there are $\mathrm{T}$ different intercept terms for $\mathrm{T}$ cross section (time), and that the variation is related to $X_{i t}$. This model is called individual time point double fixed effect model.

\subsection{Selection of models}

In empirical analysis, we usually use the Hausman test to decide whether to use the fixed effect model or the random effect model. The idea of the Hausman test is that, under the original assumption $E\left(V_{i t} \mid x_{i t}\right)=0, \hat{\beta}_{G L S}$ (generalized least squares estimator) and $\beta_{\text {Within }}$ (the least squares estimator in the group) are unbiased and consistent, but in the case of the alternative hypothesis $E\left(V_{i t} \mid x_{i t}\right) \neq 0, \hat{\beta}_{G L S}$ is not only partial but non-uniform, $\beta_{\text {Within }}$ is unbiased and consistent through the elimination of individual effects in groups.

If the original hypothesis is established, the probability limit of the two estimators is similar, whereas the probability limit is different. So Hausman tests the probability of using the difference between $\hat{\beta}_{G L S}$ and $\beta_{\text {Within }}$ to determine whether or not to reject the original hypothesis.

\section{Empirical analysis}

\subsection{Data source and sample selection}

In this paper, the annual data of all regions comes from the Guizhou statistical yearbook from 2014 to 2016 and the government work report from 2014 to 2016 issued by the official website of each district county. Part of the data is simply processed with excel tables to get schedule 1.

(1) Poverty level index (POV): indicators of poverty level include poverty incidence, income gap ratio and the FGT index. This paper starts from the convenience of obtaining data and uses the poverty rate to measure the extent of poverty.

(2) Tourism development index (TOD): a regional tourism revenues accounted for the size of the gross national product (GNP) is undoubtedly reflect the most compelling of the local tourism development index, this paper adopts the counties tourism income / GDP to reflect the status of each county tourism development.

(3) The tourists attraction index (TOA): the development of tourism is bound to be accompanied by an increase in the number of tourists, this paper adopts the counties with the number of visitors a year to illustrate the attraction of regional tourism to tourists.

(4) Ecological-economic development index (DAF): ecological tourism has become the new direction of tourism development. Therefore, we also listed the ecological-economic development as an indicator to be 
examined. The added value of ecological-economic are used to indicate here.

(5) Economic growth index (RGP): in the empirical study, GDP per capita tends to be better than that of GDP, so this paper measures economic growth by GDP per capita.

(6) Income distribution index (IG): the main body of this article is key county of Guizhou province 50 poverty alleviation and development. Considering the comparability and data item, we use urban per capita disposable income / rural per capita net income of is adopted to measure the equality of income distribution.

Based on the hypothesis that tourism development has a positive promoting effect on reducing poverty, this article selects development level of tourism, tourist attraction and ecological-economic development level as explanatory variables of the empirical model, considering the national consumption level in Guizhou county precision for poverty alleviation, the influence of long economic rights and income distribution is chosen as the control variables of the model. The variables are shown in table 1 :

Table 1. model variable scale

\begin{tabular}{ccc}
\hline Variable types & $\begin{array}{c}\text { Variable } \\
\text { name }\end{array}$ & Variable definitions \\
\hline $\begin{array}{c}\text { Interpreted } \\
\text { variable }\end{array}$ & POV & Poverty degree \\
\hline \multirow{2}{*}{$\begin{array}{c}\text { Explanatory } \\
\text { variables }\end{array}$} & TOD & Tourism development level \\
\cline { 2 - 3 } & TOA & Tourist attraction \\
\hline Control variables & RGP & $\begin{array}{c}\text { Development level of } \\
\text { agriculture, forestry and animal } \\
\text { husbandry }\end{array}$ \\
\cline { 2 - 3 } & IG & Economic growth \\
\hline
\end{tabular}

In addition, there are many factors that can reduce the incidence of poverty, such as the investment of government departments and the degree of education of residents, which we use $\mu_{i t}$ to represent the random error terms. Get the following basic model:

$P O V_{i t}=\alpha+\beta_{1} T O D_{i t}+\beta_{2} T O A_{i t}+\beta_{3} D A F_{i t}+\beta_{4} R G P_{i t}+\beta_{5} I G+\mu_{i t}$ Among them, $i=1,2,3, \ldots, 50$ represents 50 counties of poverty alleviation and development in Guizhou province; $t=2013,2014,2015$ means different years.

\subsection{Impact of tourism on targeted poverty alleviation}

\subsubsection{Hausman test}

We believe that the poverty rate will be affected by tourism development, tourist attraction, agriculture and forestry, fishery development, economic growth and income distribution, also will be affected by other factors associated with particular observation object, or period. According to the original data of tourism industry development of 50 poverty-stricken counties in Guizhou province from 2013 to 2015, the Hausman test was carried out using the Stata11.0 software, and the results were as table 2 .

Table 2. Hausman test results

\begin{tabular}{|c|c|c|c|c|}
\hline & (b) & (B) & (b-B) & $\begin{array}{c}\text { sqrt(diag } \\
\text { (V_b-V_B) })\end{array}$ \\
\hline & fe & re & Difference & S.E. \\
\hline tod & -0.6618238 & -0.4157728 & -0.246051 & 0.0495937 \\
\hline doa & -0.3819703 & -0.790043 & 0.4080727 & 0.1682498 \\
\hline daf & 0.6975831 & 0.8270739 & -0.1294908 & \\
\hline rgp & -10.34866 & -8.609656 & -1.739001 & 0.3655479 \\
\hline ig & 1.96336 & 1.96336 & -1.213396 & \\
\hline \multicolumn{5}{|c|}{ chi2(5) $=(b-B)^{\prime}\left[\left(V \_b-V \_B\right)^{\wedge}(-1)\right](b-B)=8.61$} \\
\hline \multicolumn{5}{|c|}{ Prob $>$ chi2 $=0.1255$} \\
\hline
\end{tabular}

Can be seen from table 2, Prob > chi2 $=0.1255$, Hausman test is not significant under the confidence level of $95 \%$, so accept the null hypothesis, that estimate relative to the use of fixed effects model, estimate the sample data by using random effects model is more suitable.

\subsubsection{Stochastic effect model regression}

According to the original data of 50 national povertystricken counties in Guizhou province from 2013 to 2015, the data of the Stata11.0 software was used to estimate the parameters, and the results of the fixed effect model were obtained as shown in table 3.

Table 3. Regression results of random effects model

\begin{tabular}{ccccccc}
\hline pov & Coef. & Std. Err. & $\mathrm{t}$ & $\mathrm{P}>|\mathrm{t}|$ & [95\% Conf. & Interval] \\
\hline tod & -0.4157728 & 0.1061118 & -3.92 & 0 & -0.6237482 & -0.2077975 \\
doa & -0.790043 & 0.3230725 & -2.45 & 0.014 & -1.423253 & 0.1568325 \\
daf & 0.0270739 & 0.2466582 & 3.35 & 0.268 & 0.3436327 & 1.310515 \\
rgp & -8.609656 & 0.8618021 & -9.99 & 0 & -10.29876 & -6.920555 \\
ig & 3.176756 & 1.476361 & 2.15 & 0.031 & 0.2831411 & 6.070371 \\
_cons & 30.64046 & 5.939359 & 5.16 & 0 & 18.99953 & 42.28139 \\
& sigma_u & & & 4.1794156 \\
\multicolumn{4}{c}{ sigma_e } \\
rho & & & & 1.3203599 \\
$c$ & corr(u_i,X)=0(assumed) & Prob>chi2=0.0000 \\
\hline
\end{tabular}

From the point of significance level, tourism development, tourist attraction, economic rights and income distribution coefficient of indicators 


\section{S. Li, M. Zhang}

significantly long is not zero; $\mathrm{P}$ value is less than 0.05 . It is indicates that tourism development index and tourist attraction index coefficient is zero the possibility of less than 5\%; And the $\mathrm{P}$ value of ecologicaleconomic development index is 0.268 , shows an ecological-economic development indicators under $26.8 \%$ probability coefficient may be zero, $73.2 \%$ of the time coefficient is not zero, so the index can't pass the test of significance and should be deleted from the model. Therefore, tourism development, tourist attraction, long economic rights and income distribution have significant influence to the poverty rate of 50 counties in Guizhou, its elasticity were $0.4158,0.79$, $8.6097,0.4158$, while there is no significant impact on ecological-economic development indicators.

\subsubsection{Hausman test after deleting the no significant}

In the original data, the Ecological-economic development index (DAF) was removed and the Hausman test was carried out with the Stata11.0 software. The results were shown in table 4 .

Table 4. Hausman test results

\begin{tabular}{|c|c|c|c|c|}
\hline & (b) & (B) & (b-B) & $\begin{array}{c}\text { sqrt(diag } \\
\left.\left(\mathrm{V} \_b-V \_B\right)\right)\end{array}$ \\
\hline & fe & re & Difference & S.E. \\
\hline tod & -0.6296584 & -0.4067843 & -0.2228471 & 0.0547451 \\
\hline doa & -0.2666472 & -0.7460522 & 0.4794049 & 0.1825376 \\
\hline rgp & -11.43676 & -9.641491 & -1.795274 & 0.3757357 \\
\hline ig & 2.748999 & 4.232755 & -1.483756 & \\
\hline \multicolumn{5}{|c|}{ chi2(4) $=(b-B)^{\prime}\left[\left(V \_b-V \_B\right)^{\wedge}(-1)\right](b-B)=3.84$} \\
\hline \multicolumn{5}{|c|}{ Prob $>$ chi $2=0.4279$} \\
\hline
\end{tabular}

Can be seen from table 4, Prob > chi2 $=0.4279$, Hausman test is not significant under the confidence level of $95 \%$, so accept the null hypothesis, that estimate relative to the use of fixed effects model, estimate the sample data by using random effects model is more suitable.

\subsubsection{Regression of random effect model}

According to the 2013 to 2015, 50 state-level povertystricken counties in Guizhou raw data, delete the ecological-economic development indicators, again use Stata11.0 software for parameter estimation, concluded as shown in table 5 the regression results of random effects model.

Table 5. Regression results of random effects model

\begin{tabular}{ccccccc}
\hline pov & Coef. & Std. Err. & $\mathrm{t}$ & $\mathrm{P}>|\mathrm{t}|$ & {$[95 \%$ Conf. } & Interval] \\
\hline tod & -0.4067843 & 0.1095295 & -3.71 & 0 & -0.6214581 & -0.1921105 \\
doa & -0.7460522 & 0.3336913 & -2.24 & 0.025 & -1.400075 & 0.0920293 \\
rgp & -9.641491 & 0.8373706 & -11.51 & 0 & -11.28271 & -8.000274 \\
ig & 4.232755 & 1.477959 & 2.68 & 0.004 & 1.336009 & 7.129501 \\
_cons & 34.80641 & 5.991294 & 5.81 & 0 & 23.06369 & 46.54914 \\
sigma_u & \multicolumn{5}{c}{4.4968712} \\
sigma_e & 1.3852328 \\
rho & \multicolumn{5}{c}{0.913333} \\
\multicolumn{5}{c}{ corr(u_i,X)=0(assumed) } & Prob>chi2 $=0.0000$ \\
\hline
\end{tabular}

From table 5, we can see from the estimated coefficients of variables, tourism development indicators, tourist attraction indicators and economic growth indicators are negatively correlated with poverty rates in Guizhou poverty-stricken counties. It is suggested that the increase of tourism development, tourist attraction and economic rise can slow the poverty status of Guizhou national poverty-stricken counties. Income distribution and poverty rate were positively related, namely the wider income distribution gap , the higher incidence of poverty-stricken counties in Guizhou, which conform to the real economic significance. From the point of the estimated coefficients of variables, the $\mathrm{P}$ values of tourism development, tourist attraction, long economic rights and income distribution indicators were less than 0.05 , which is under the $95 \%$ confidence level were significantly. Therefore, the tourism development index and tourist attraction index of explanatory variables have a positive effect on reducing the poverty rate in Guizhou poverty-stricken counties. Therefore, the regression equation can be obtained:

$P O V_{i t}=34.8064-0.4068 \Gamma O D_{i t}-0.7461 T O A_{t}-9.6415 R G P_{i t}+4.2328 I G+\mu_{i t}$

\section{Conclusion}

By using the stochastic effect model for empirical research, we find that the development of tourism, the attraction of tourists and the increase of economic growth can slow the poverty situation in Guizhou's national poverty-stricken counties, the wider income distribution gap, the higher incidence of povertystricken counties in Guizhou. Therefore, in addition to increasing input in order to promote the development of the tourism industry, increasing the visibility of tourist attractions or developing tourism economy is also an important way to reduce poverty. From the significance level, it is the development of tourism industry and 
economic rise of the economic rise, which has a significant influence on the poverty rate in Guizhou. The tourism population is slightly lower, which may be caused by the uneven tourism consumption level in Guizhou province.

Through the establishment of panel data model research, it is shown that increasing the investment of tourism industry in all regions has a certain positive effect on reducing the incidence of poverty. Investment is more than just the poverty alleviation office government to invest more, but it can also encourage entrepreneurs to help the poor and provide funds or technology for win-win results. At the same time, the government should increase financial input, pay more attention to the construction of public infrastructure and alleviate the road traffic problems in remote areas.

In recent years, scholars have done a lot of research on poverty, but there are few studies on the incidence of poverty. Based on the tourism industry, this paper collects panel data of 50 counties in Guizhou. After simple processing of the data, a panel data model is established, we compared the advantages and disadvantages to determine the final proper model, and then draw the conclusion. But because my ability is limited, in the depth of the research and analysis, variable selection method and depth is relatively shallow, so this paper in terms of data extension and influencing factors of development still has a certain research space.

\section{Propose}

Based on the above results, the data of poverty incidence in 88 counties (cities and districts) of Guizhou Province are analyzed. It is found that the change of poverty incidence is influenced by a series of influencing factors. Some of the factors we consider can be adjusted through national and local policies... in the process of poverty reduction and development, while ensuring stable and rapid economic growth in all districts and counties of Guizhou Province, we can also adopt local pro-poor and pro-agricultural policies and social security. Other factors affecting poverty can be changed in terms of multi-channel financing. This not only guarantees stable economic growth, but also improves people's living standards. To reduce the scope of poverty and reduce the degree of poverty, to achieve stable economic growth income steadily improve poverty reduction effect of good win-win situation. This paper studies the incidence of poverty in all counties and cities of the province as the starting point. According to the situation of Guizhou Province, the countermeasures and suggestions for poverty reduction in Guizhou Province are put forward.

(1) In terms of economic development, it can be roughly seen from the distribution map of poverty in various regions that key poverty counties in Guizhou Province are mainly located in remote areas with low economic levels, so we must first improve the overall poverty situation in the whole province. First of all, it is necessary to grasp the lifeblood of the overall economy, vigorously develop the market economy, encourage technological innovation and research and development, move closer to technology-intensive industries, rationally develop the economy and implement differentiated economic development according to the geographical regions and resource advantages of the 88 counties. In addition, the development of economy in the whole province should grasp the rational and sustainable development mode, protect the construction of ecological civilization, rationally utilize the exploitation of resources, and realize the sustained and steady growth of the economy.

(2) The province has actively promoted the development of industrialization, increased employment posts, reduced the urban unemployment rate, and provided job opportunities for migrant workers in cities. However, at present, the income gap between urban and rural residents is widening, leading to a polarization between the rich and the poor. Seriously restricting the development of rural economy, and because the various social security systems for migrant workers are not perfect, it is easy to cause the old labor force to lose and return to poverty again. Therefore, in the course of promoting the urbanization and industrialization construction actively in the province, Actively ensure the employment of rural personnel and low-income urban residents, feed modern agricultural production with industry, and promote the upgrading and transformation of rural industries by the development of urban economy. It is not a jump process that needs to increase the overall development of urban and rural areas, adjust the traditional urban-rural dual economic structure, enhance the interaction between urban and rural areas, and actively guide and cooperate with each other, so as to put into practice the system of ensuring the overall development of urban and rural areas 
formulated by the state. Do not allow national preferential policies from the central to local gradually devalued.

(3) Research on panel data model shows that increasing fixed asset investment in various regions has a certain positive effect on reducing the incidence of poverty. Since the new round of poverty alleviation work has been carried out by the Public Office of the State Council for Poverty Alleviation, efforts to alleviate poverty and development have been intensified. Through such effective means as continuous development, village promotion and industrial poverty alleviation, we should increase investment in povertystricken areas. Investment is not just an increase in government investment in poverty alleviation offices and an increase in rural financing channels. At the same time, entrepreneurs can be encouraged to help industries in poor areas, providing capital or technology to achieve win-win results. The government should increase financial expenditure, increase the construction of rural public infrastructure, and effectively alleviate the problem of water consumption for agricultural production in high mountain areas in summer.

(4) Rural workers go to cities to work and raise family income effectively, but the problem of the disadvantaged situation of children left behind and the elderly living alone in rural areas arising gradually from going out of the young labor force should be guaranteed both to increase their income and to ensure a smooth solution to such problems. We must vigorously support the development of township and township industries in counties, cities and towns, actively build local characteristic industries in combination with local advantages, adopt rural cooperative management methods, and integrate resources for long-term development; in addition, farmers who are willing to engage in secondary and tertiary industries, Rely on immigrants to expand towns and new rural construction, through industrial skills training, promote employment and other forms of industrialization poverty alleviation, adhere to rural areas to adhere to rural poverty alleviation labor force nearby employment principle, avoid rural labor force outflow, raise local economic level strength.

\section{Acknowledgements}

This paper is one of the periodic results of the study on The Study on the Efficiency and Mechanism of
Financial Support for the Poverty-alleviation of Guizhou Specialty Industry.

\section{References}

[1] Chen F. Statistical analysis of poverty rate in Guizhou Province. Guizhou University of Finance and Economics, 2014.

[2] Zhang L J. Study on the implementation of precision poverty alleviation policy of county-level government. Zhengzhou University, 2016.

[3] Tang Q Q. Research on the internal mechanism and efficiency of financial support for strategic emerging industries. Guizhou University of Finance and Economics, 2016.

[4] Liu H Y. Great poverty alleviation: practice and suggestion of public welfare organizations. Social Sciences Literature Publishing House, 2011.

[5] He X. Poverty Alleviation in Zang People's Regions of Yunnan Province from the Perspective of Accurate Anti-poverty. International Conference on Society Science. 2017.

[6] Yang Y, Zhang A. Precise poverty alleviation problems and countermeasures in Xinjiang Uygur Autonomous Region. International Education, Economics, Social Science, Arts, Sports and Management Engineering Conference. 2016.

Appendix A. Related index data of 50 state-level poor counties in Guizhou province in the past 3 years

\begin{tabular}{cccccccc}
\hline Area & Year & POV & FS & FE & FSR & RGP & IG \\
\hline Liuzhi & 2013 & 0.1997 & 1.5620 & 1.7100 & 0.0000 & 2.0371 & 3.2719 \\
Special & 2014 & 0.1698 & 1.3608 & 2.0656 & 0.0000 & 2.5648 & 3.0126 \\
Zone & 2015 & 0.1390 & 1.3238 & 2.3333 & 0.0000 & 2.9673 & 2.9963 \\
Shuich & 2013 & 0.2886 & 4.7495 & 0.5234 & 0.0000 & 1.8619 & 3.3206 \\
eng & 2014 & 0.2481 & 5.2849 & 0.5956 & 0.0000 & 2.4496 & 3.0630 \\
County & 2015 & 0.2100 & 5.2321 & 0.6428 & 0.0000 & 2.7828 & 3.0200 \\
& 2013 & 0.2349 & 0.9845 & 1.9424 & 0.0000 & 3.5049 & 3.1507 \\
Pan & 2014 & 0.1879 & 0.9092 & 2.3680 & 0.0000 & 4.0896 & 2.9045 \\
County & 2015 & 0.1430 & 1.0151 & 2.2980 & 0.0000 & 4.5397 & 2.8861 \\
Zheng & 2013 & 0.2162 & 2.3025 & 0.7822 & 0.0000 & 1.1360 & 3.4571 \\
an & 2014 & 0.1638 & 2.0470 & 0.8642 & 0.0000 & 1.5592 & 2.9436 \\
Count & 2015 & 0.1510 & 2.3394 & 0.8765 & 0.0000 & 1.8475 & 2.9222 \\
Daozh & 2013 & 0.1961 & 2.4699 & 0.7183 & 0.0000 & 1.3184 & 3.6118 \\
en & 2014 & 0.1636 & 2.3703 & 0.7921 & 0.0000 & 1.6275 & 2.9399 \\
County & 2015 & 0.1160 & 2.3788 & 0.8025 & 0.0000 & 1.9703 & 2.9214
\end{tabular}


Wuchu $2013 \quad 0.23532 .57310 .72070 .00001 .08523 .6755$ an $\quad \begin{array}{lllllll}2014 & 0.1874 & 2.4613 & 0.8310 & 0.0000 & 1.3473 & 2.9448\end{array}$ County $2015 \quad 0.13702 .7818 \quad 0.77800 .0000 \quad 1.60982 .9316$ $2013 \quad 0.22841 .59731 .42990 .00001 .75803 .5500$

Xishui

County

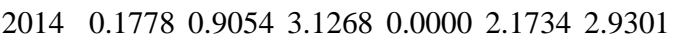
$2015 \quad 0.13201 .69251 .69570 .00002 .46622 .9142$ $2013 \quad 0.2547 \quad 1.55791 .25530 .00001 .56923 .3232$

Puding

County $\begin{array}{lllllll}2014 & 0.2077 & 1.4798 & 1.7643 & 0.0000 & 1.8760 & 3.2807\end{array}$ $\begin{array}{lllllll}2015 & 0.1510 & 1.6890 & 1.4374 & 0.0000 & 2.1876 & 3.2072\end{array}$

Zhenni $2013 \quad 0.25742 .1540 \quad 0.7718 \quad 1.00001 .83143 .3715$

ng $\quad 2014 \quad 0.2176 \quad 1.87751 .10521 .00002 .25443 .3173$ County $2015 \quad 0.1870 \quad 1.9718 \quad 1.0534 \quad 1.0000 \quad 2.6310 \quad 3.2871$

Guanli $2013 \quad 0.28651 .59570 .58690 .00001 .66783 .3401$

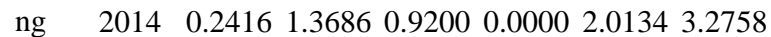

$\begin{array}{lllllllll}\text { County } 2015 & 0.1800 & 1.5269 & 0.8919 & 0.0000 & 2.4092 & 3.2343\end{array}$ $\begin{array}{llllllll}2013 & 0.2868 & 1.8025 & 0.6788 & 0.0000 & 1.3071 & 3.3083\end{array}$

Ziyun

County $\begin{array}{lllllll}2014 & 0.2427 & 1.6404 & 0.9083 & 0.0000 & 1.6589 & 3.2834\end{array}$ $\begin{array}{lllllll}2015 & 0.1930 & 1.8093 & 0.9055 & 0.0000 & 1.8985 & 3.1803\end{array}$ $2013 \quad 0.27761 .08461 .56320 .00001 .6673 \quad 3.3181$

$\begin{array}{llllllll}\text { Dafang } 2014 & 0.2351 & 0.9710 & 1.8221 & 0.0000 & 2.0372 & 3.2741\end{array}$

$\begin{array}{llllllll}\text { County } & 2015 & 0.1910 & 1.0792 & 1.6908 & 0.0000 & 2.2897 & 3.2005\end{array}$ $2013 \quad 0.31951 .53691 .86840 .00001 .37123 .4599$

Zhijin

County $\begin{array}{lllllll}2014 & 0.2732 & 1.4326 & 2.4169 & 0.0000 & 1.7361 & 3.3147\end{array}$

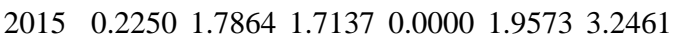

Nayon $2013 \quad 0.26850 .94342 .34420 .0000 \quad 1.83703 .5131$ g $\quad 2014 \quad 0.22390 .90222 .7703 \quad 0.00002 .20953 .4727$ $\begin{array}{llllllll}\text { County } & 2015 & 0.1810 & 0.9971 & 2.3715 & 0.0000 & 2.5354 & 3.3979\end{array}$ Weinin $2013 \quad 0.24050 .91142 .26880 .00000 .97673 .3157$ g $\quad \begin{array}{lllllll}2014 & 0.1863 & 0.8969 & 2.2487 & 0.0000 & 1.1992 & 3.2773\end{array}$ $\begin{array}{llllllll}\text { county } & 2015 & 0.1450 & 0.9656 & 1.8456 & 0.0000 & 1.4882 & 3.1898\end{array}$ Hezha $2013 \quad 0.26051 .28041 .4626 \quad 0.00001 .01383 .5010$ ng $\quad 2014 \quad 0.2177 \quad 1.09151 .66510 .00001 .39373 .4606$ County $2015 \quad 0.17901 .15391 .3654 \quad 0.0000 \quad 1.71123 .3678$ $\begin{array}{lllllllll}\text { Jiangk } & 2013 & 0.2350 & 2.6010 & 1.1867 & 0.0000 & 1.6017 & 3.3829\end{array}$ $\begin{array}{llllllll}\text { ou } \quad 2014 & 0.1878 & 2.4635 & 1.5219 & 0.0000 & 1.9289 & 3.2618\end{array}$ $\begin{array}{llllllll}\text { County } 2015 & 0.1380 & 2.3778 & 1.4809 & 0.0000 & 2.3858 & 3.2857\end{array}$ $\begin{array}{lllllllll}\text { Shiqia } & 2013 & 0.2586 & 2.0468 & 0.7560 & 0.0000 & 1.2592 & 3.3528\end{array}$ n $\quad 2014 \quad 0.21201 .94250 .85010 .00001 .56573 .1903$

County $2015 \quad 0.16502 .1168 \quad 0.7530 \quad 0.0000 \quad 1.9547 \quad 3.1842$ $\begin{array}{llllllll}2013 & 0.2543 & 2.0290 & 1.3253 & 0.0000 & 1.4778 & 3.5352\end{array}$ $\begin{array}{lllllllll}\text { Sinan } & 2014 & 0.2132 & 1.9354 & 1.4767 & 0.0000 & 1.7667 & 3.2799\end{array}$ $\begin{array}{llllllll}\text { County } & 2015 & 0.1640 & 2.0426 & 1.3880 & 0.0000 & 2.0282 & 3.2694\end{array}$ Yinjian $2013 \quad 0.23642 .09461 .0596 \quad 0.00001 .70013 .4483$ g $\quad 2014 \quad 0.1913 \quad 1.9265 \quad 1.2793 \quad 0.00002 .0722 \quad 3.2351$ County $2015 \quad 0.1430 \quad 1.9747 \quad 1.19130 .0000 \quad 2.6070 \quad 3.2720$

Dejian $2013 \quad 0.28801 .43841 .18930 .00001 .63413 .6942$ g $\quad 2014 \quad 0.25791 .40751 .3866 \quad 0.00001 .98523 .3293$

County $2015 \quad 0.20201 .5073 \quad 1.3448 \quad 0.0000 \quad 2.2807 \quad 3.3124$ $\begin{array}{lllllll}2013 & 0.2713 & 1.6461 & 1.4640 & 0.0000 & 1.3106 & 3.5447\end{array}$ Yanhe $2014 \quad 0.22951 .50261 .69620 .00001 .61253 .3216$ $\begin{array}{llllllll}\text { County } & 2015 & 0.1700 & 1.6187 & 1.5581 & 0.0000 & 1.8766 & 3.2763\end{array}$ $\begin{array}{lllllllll}\text { Songta } & 2013 & 0.2333 & 1.7564 & 1.1832 & 0.0000 & 1.4971 & 3.5246\end{array}$ o $\quad 2014 \quad 0.18891 .52951 .4697 \quad 0.00001 .8223 \quad 3.2933$ County $2015 \quad 0.14201 .6677 \quad 1.33390 .0000 \quad 2.1132 \quad 3.2999$ Xingre $2013 \quad 0.20701 .46651 .59320 .00001 .8413 \quad 3.3526$ $\begin{array}{llllllll}\text { n } & 2014 & 0.1612 & 1.4060 & 1.9500 & 0.0000 & 2.1951 & 3.2807\end{array}$ County $2015 \quad 0.1060 \quad 1.4848 \quad 0.8705 \quad 0.0000 \quad 2.7007 \quad 3.2391$ Pu' an $2013 \quad 0.19631 .56881 .16770 .00001 .67413 .6717$ County $2014 \quad 0.1517 \quad 1.49991 .4472 \quad 0.0000 \quad 1.9705 \quad 3.4866$

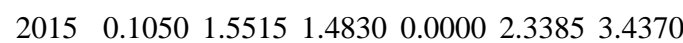

Qinglo $2013 \quad 0.3741 \quad 1.4027 \quad 1.4547 \quad 0.00001 .49563 .8001$ ng $\quad \begin{array}{llllllll}2014 & 0.3277 & 1.3350 & 1.7043 & 0.0000 & 1.7919 & 3.6365\end{array}$ $\begin{array}{llllllll}\text { County } 2015 & 0.2570 & 1.3734 & 2.1179 & 0.0000 & 2.2231 & 3.5218\end{array}$ Zhenfe $2013 \quad 0.25621 .42041 .00730 .00002 .05213 .4162$ ng $\quad 2014 \quad 0.20651 .3977 \quad 1.16010 .00002 .50593 .2789$ County $2015 \quad 0.16101 .33130 .6826 \quad 0.0000 \quad 2.9813 \quad 3.2789$ Wang $2013 \quad 0.3302 \quad 2.19440 .71230 .0000 \quad 1.02324 .0494$ mo $\quad 2014 \quad 0.27821 .95580 .84950 .00001 .45443 .7188$ County $2015 \quad 0.21201 .84250 .6996 \quad 0.00001 .90233 .6595$ Cehen $2013 \quad 0.32732 .39240 .65030 .00001 .21013 .8645$ g $\quad 2014 \quad 0.29172 .2186 \quad 0.7470 \quad 0.00001 .5128 \quad 3.6773$

County $2015 \quad 0.2090 \quad 1.9262 \quad 2.09200 .00001 .92213 .6284$ $\begin{array}{llllllll}2013 & 0.1877 & 1.3995 & 0.8662 & 0.0000 & 1.7737 & 3.4391\end{array}$

$\begin{array}{lllllllll}\text { Anlong } & 2014 & 0.1440 & 1.3832 & 1.0388 & 0.0000 & 2.0314 & 3.2890\end{array}$ $\begin{array}{llllllll}\text { County } & 2015 & 0.0940 & 1.7626 & 0.4974 & 0.0000 & 2.4505 & 3.2979\end{array}$ Huang $\begin{array}{lllllll}2013 & 0.3004 & 1.9860 & 0.7621 & 0.0000 & 1.1815 & 3.7572\end{array}$ ping $\quad \begin{array}{lllllll}2014 & 0.2790 & 1.8816 & 0.9165 & 0.0000 & 1.4245 & 3.5437\end{array}$ County $2015 \quad 0.23002 .06050 .6161 \quad 0.00001 .66213 .4960$ Shibin $2013 \quad 0.31501 .62301 .15580 .00001 .7763 \quad 3.3146$ g $\quad 2014 \quad 0.26812 .06550 .77840 .00002 .09103 .1398$ $\begin{array}{llllllll}\text { County } 2015 & 0.2190 & 2.0764 & 1.1981 & 0.0000 & 2.3598 & 3.1285\end{array}$ $\begin{array}{lllllll}2013 & 0.3379 & 1.7702 & 1.1428 & 0.0000 & 1.6071 & 3.5407\end{array}$ $\begin{array}{lllllllll}\text { Sansui } & 2014 & 0.2909 & 1.6284 & 1.6463 & 0.0000 & 1.9833 & 3.3523\end{array}$ $\begin{array}{llllllll}\text { County } & 2015 & 0.2380 & 1.8556 & 1.4249 & 0.0000 & 2.2779 & 3.3075\end{array}$

$\begin{array}{llllllll}\text { Cengo } & 2013 & 0.2637 & 1.9118 & 1.0224 & 0.0000 & 1.6613 & 3.5417\end{array}$

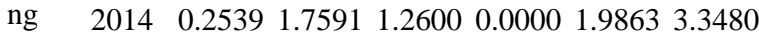


S. Li, M. Zhang

County $2015 \quad 0.1990 \quad 2.2469 \quad 1.02100 .0000 \quad 2.27793 .2971$

Tianzh 20130.31761 .73510 .98350 .00001 .88713 .3986

u $\quad 2014 \quad 0.27651 .64701 .11700 .0000 \quad 2.2678 \quad 3.2196$

County $2015 \quad 0.22501 .68091 .1953 \quad 0.00002 .58573 .1822$ $\begin{array}{llllllll}2013 & 0.3275 & 2.0483 & 0.5913 & 0.0000 & 1.6432 & 3.8270\end{array}$

$\begin{array}{llllllll}\text { Jinping } & 2014 & 0.2854 & 1.9548 & 0.6780 & 0.0000 & 1.9746 & 3.5833\end{array}$

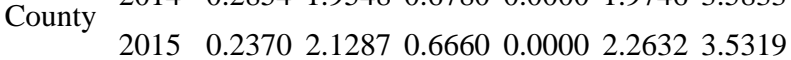
$\begin{array}{lllllll}2013 & 0.3248 & 1.7745 & 0.9054 & 0.0000 & 1.4525 & 3.7346\end{array}$

Jianhe

County $\begin{array}{llllllll}2014 & 0.2829 & 1.7187 & 1.0360 & 0.0000 & 1.7250 & 3.5258\end{array}$ $\begin{array}{lllllll}2015 & 0.2370 & 1.8588 & 0.9957 & 0.0000 & 1.9953 & 3.4880\end{array}$

Taijian $2013 \quad 0.3201 \quad 2.61501 .29020 .00001 .6713 \quad 3.9039$ g $\quad 2014 \quad 0.28782 .3378 \quad 1.6208 \quad 0.0000 \quad 1.9982 \quad 3.6416$ County $2015 \quad 0.19903 .0975 \quad 1.1386 \quad 0.0000 \quad 2.29313 .6023$ $\begin{array}{llllllll}2013 & 0.2738 & 2.1670 & 0.8683 & 0.0000 & 1.2132 & 3.6510\end{array}$

$\begin{array}{lllllllll}\text { Liping } & 2014 & 0.2448 & 1.9845 & 1.0485 & 0.0000 & 1.4719 & 3.4456\end{array}$

$\begin{array}{llllllll}\text { County } & 2015 & 0.2250 & 2.0841 & 1.0524 & 0.0000 & 1.7300 & 3.4425\end{array}$

Rongji $2013 \quad 0.36222 .15860 .9597 \quad 0.00001 .23663 .7655$ ang $\quad \begin{array}{llllllll}2014 & 0.3373 & 1.9742 & 1.1567 & 0.0000 & 1.4460 & 3.5307\end{array}$ $\begin{array}{llllllll}\text { County } 2015 & 0.2760 & 2.1531 & 1.0975 & 0.0000 & 1.6868 & 3.4802\end{array}$ $\begin{array}{lllllllll}\text { Congji } 2013 & 0.3168 & 1.4098 & 1.5943 & 0.0000 & 1.1850 & 3.5328\end{array}$ ang $\quad \begin{array}{llllllll}2014 & 0.2901 & 1.3438 & 1.8033 & 0.0000 & 1.4128 & 3.3457\end{array}$ $\begin{array}{llllllll}\text { County } & 2015 & 0.2390 & 1.4400 & 1.6609 & 0.0000 & 1.6614 & 3.3071\end{array}$ $\begin{array}{llllllll}\text { Leisha } & 2013 & 0.2798 & 2.0373 & 0.8388 & 0.0000 & 1.4951 & 3.5638\end{array}$ $\begin{array}{llllllll}\text { n } & 2014 & 0.2648 & 2.1268 & 0.8765 & 0.0000 & 1.7947 & 3.3613\end{array}$

$\begin{array}{llllllll}\text { County } & 2015 & 0.2080 & 2.3375 & 0.8282 & 0.0000 & 2.0324 & 3.3134\end{array}$

Majian $2013 \quad 0.3768 \quad 1.9331 \quad 1.06420 .00001 .54513 .7132$

g $\quad 2014 \quad 0.32762 .31090 .62750 .00001 .82803 .5102$

County $2015 \quad 0.20602 .82890 .53940 .00002 .17283 .4473$

Danzh $2013 \quad 0.33732 .37461 .32050 .00001 .47483 .7290$

ai $\quad \begin{array}{lllllll}2014 & 0.2924 & 2.2849 & 1.5348 & 0.0000 & 1.7435 & 3.5065\end{array}$

$\begin{array}{llllllll}\text { County } 2015 & 0.2381 & 2.4103 & 1.5601 & 0.0000 & 1.9967 & 3.4564\end{array}$ $\begin{array}{lllllll}2013 & 0.3092 & 1.8763 & 1.0938 & 0.0000 & 2.4050 & 3.2383\end{array}$

Libo

County $\begin{array}{lllllll}2014 & 0.2556 & 1.7939 & 1.2754 & 0.0000 & 3.2619 & 3.0447\end{array}$ $\begin{array}{lllllll}2015 & 0.2109 & 1.9702 & 1.2838 & 0.0000 & 3.5620 & 3.0310\end{array}$

Dusha $2013 \quad 0.27301 .9787 \quad 0.74900 .00001 .62143 .2014$ n $\quad 2014 \quad 0.2273 \quad 1.76620 .99720 .0000 \quad 2.0422 \quad 2.9973$ $\begin{array}{lllllllll}\text { County } 2015 & 0.1759 & 2.0870 & 0.9221 & 0.0000 & 2.3035 & 2.9623\end{array}$ Pingta $2013 \quad 0.3151 \quad 1.64251 .20500 .00001 .35713 .2600$ $\begin{array}{lllllllll}\text { ng } \quad 2014 & 0.2598 & 1.5143 & 1.3828 & 0.0000 & 1.7760 & 3.0491\end{array}$ County $2015 \quad 0.19552 .0246 \quad 1.1493 \quad 0.0000 \quad 1.98853 .0271$ Luodia $2013 \quad 0.3551 \quad 1.67311 .19051 .00001 .59483 .0516$ $\begin{array}{lllllllll}\text { n } & 2014 & 0.3027 & 1.5089 & 1.4432 & 1.0000 & 1.9817 & 2.8634\end{array}$ $\begin{array}{llllllll}\text { County } & 2015 & 0.2416 & 1.6755 & 1.4443 & 1.0000 & 2.2175 & 2.8479\end{array}$
Changs $2013 \quad 0.31831 .46071 .38450 .00001 .71663 .1800$ hun $\quad 2014 \quad 0.26561 .30311 .8096 \quad 0.00002 .22112 .9792$ County $2015 \quad 0.2052 \quad 1.7363 \quad 1.3846 \quad 0.00002 .46852 .9309$ $\begin{array}{lllllll}2013 & 0.3562 & 1.8810 & 1.0051 & 0.0000 & 1.1991 & 3.2038\end{array}$ $\begin{array}{lllllllll}\text { Sandu } & 2014 & 0.3230 & 1.6408 & 1.1906 & 0.0000 & 1.6361 & 2.9842\end{array}$ $\begin{array}{llllllll}\text { county } & 2015 & 0.2526 & 1.9236 & 1.0769 & 0.0000 & 1.8281 & 2.9600\end{array}$ 